FMMB 2014 - First International Conference. September 22-24, 2014. Noumé, New Caledonia

\title{
Evaluating Management Scenarios for Fished Resources of the New Caledonian Lagoon Using a Spatially-Explicit Model
}

\author{
Preuss Bastien ${ }^{1}$, Pelletier Dominique ${ }^{2}$, Wantiez Laurent ${ }^{1}$
}

${ }^{1}$ EA 4243, LIVEUniversité de la Nouvelle-Calédonie Nouméa, New Caledonia

2 IFREMER, UR LEAD BP 2059Nouméa Cedex, New Caledonia

Email addresses : bastien.preuss@gmail.com ; laurent.wantiez@univ-nc.nc ; dominique.pelletier@ifremer.fr

\begin{abstract}
:
In the New Caledonian lagoon, fish populations live in a highly-fragmented habitat and seascape, and many are exploited by commercial, recreational and subsistence fishers. Although fishing has been increasing over decades, fisheries sustainability has not been assessed. We used the ISIS-Fish tool to build a spatially-explicit dynamic model for two major fish resources: spangled emperor and coral trout. The model was constructed and parameterized from many existing data habitat, fish populations, and fishing pressures. After calibration, it was used to simulate the outcomes of several management scenarios including MPA, size limitation, and increase in commercial fisher number. Results showed that depending on the species, an MPA could result in a significant resource increase within its boundaries. Size limitation highly reduced line fishing catches, but its benefits depended on the survival rate of released fish. Increasing the number of commercial fishers significantly affected spangled emperor but not coral trout.
\end{abstract}

Keywords: fish population dynamics, spatially-explicit model, management scenario assessment, spangled emperor, coral trout, New Caledonian lagoon 


\section{Introduction}

Coastal areas are subject to increasing demographic pressure, and they host activities other than fisheries. Integrating principles of sustainable development to limit he loss of environmental resources is a challenge for the forthcoming years, as e.g. stated in the Millenium Goals (http://www.un.org/milleniumgoals). To reach this goal, it is necessary to implement management options that ensure fisheries sustainability. Marine Protected Areas (MPA), constitute a key policy for the management of coastal fisheries and ecosystems, because zoning of uses is often indispensable to achieve apparently conflicting goals such as biodiversity conservation and sustainable development of economic activities, including fisheries. Other management options as gear restriction or limitation of size of professional fisheries are also frequently used by decision makers.

In New Caledonia, two thirds of the human population lives in or close to Noumea city. Due to fishing pressure in the surrounding lagoon, conservation measures such as no-take marine reserves, have long been established to prevent excessive fishing pressure. Yet, the sustainability of the current exploitation level has not been assessed, particularly under a growing demographic pressure.

The consequences of additional and alternative management options can be investigated using e.g. simulation models of fisheries dynamics. Spatially explicit population dynamic models are particularly relevant in this context because of the spatial heterogeneity of resources and fishing, especially in a fragmented coral reef habitat.

Among existing spatial fisheries models, the ISIS-Fish model [1] was designed to be parameterized from existing knowledge on fish resources and corresponding fisheries. In the present paper, we used the ISIS-Fish tool to build a spatially-explicit dynamic model for two major fish resources: spangled emperor (Lethrinus nebulosus, Forsskal, 1775) and coral trout (Plectropomus leopardus, Lacepède, 1802). After calibration, it was used to simulate the outcomes of several management scenarios including MPA, size limitation, and increase fishing effort (number of commercial fishermen).

\section{Material and methods}

ISIS-Fish relies on a grid of identical cells from which model zones are defined. The extent of the modelled area was defined to include the known features of population dynamics of the species studied. This large area encompasses the southwest lagoon of New Caledonia from fringing reef to barrier reef. Cell size was defined as a trade-off between a) the ability to identify some important features of habitat and small existing marine reserves and b) computational constraints, and resulting in a square grid side of 0.01 degree. 
For mobile species, modeling population dynamics requires to account and formalize mobility. Mobility coefficients were defined to characterise fish movement between model zones, with regard to the spawning season and dispersion. Spangled emperor is mobile and macrocarnivore. It exhibits a strong preference for sea grass and sandy bottom habitats, and it changes habitat according to ontogeny, while coral trout is piscivore, mainly sedentary and preferably found on coral reef habitats (see references in [2]). The two resources are targeted by distinct fishing métiers, spangled emperor being caught by line fishing, while coral trout is mostly caught by spearfishers.

Professional and recreational fishing were characterised using respectively fisheries data and interview data.

The model was calibrated from existing abundance indices obtained from underwater visual counts using the Simplex algorithm.

Sensitivity analysis was achieved using the group-screening technique [3] within a fractional design [4]. A total of 140 parameters were identified as uncertainty-prone, 77 for population submodel and 63 for fishery submodel. These parameters were clustered into 18 groups bearing similar consequences on model outputs. For each parameter, the range of variation considered was either the minimum and maximum values found in the literature, or alternatively a $20 \%$ range around the nominal parameter value.

\section{Results}

Simulation results showed that the consequences of alternative scenarios on population dynamics could not all be distinguished, in relation with parameter uncertainty. Under certain assumptions and depending on the species, the proposed MPA design could result in increased population abundances within its boundaries. The minimum legal size scenario strongly reduced line fishing catches, and spangled emperor and coral trout biomass only benefitted from the latter scenario. But outcomes depended on the survival rate of released fish. Increasing the number of professional fishers significantly affected spangled emperor populations, but not coral trout. Other MPA scenario could be investigated from the model.

Uncertainties on coral trout recruitment resulted in contrasted biomass trajectories, depending on the assumption, whatever the management scenario.

This work shows that, from existing data, it was possible to parameterize a complex spatial model for two major fished resources. The model enabled to confront the consequences of a range of plausible management scenarios. These consequences depend on existing uncertainties, some of which are tied to poorly-quantified aspects of population dynamics. The study thus points out critical gaps in resource knowledge which need to be addressed to better appraise population dynamics under a range of management scenarios.

\section{Bibliography}

1. Pelletier, D., S. Mahévas, H. Drouineau, Y. Vermard, O. Thébaud, O. Guyader, B. Poussin. 2009. Evaluation of the bioeconomic sustainability of complex fisheries under a wide range of policy options using ISIS-Fish. Ecological Modelling 220, 1013-1033. DOI:10.1016/j.ecolmodel.2009.01.007.

2. Preuss, B. 2012. Évaluation de scénarios de gestion des ressources du lagon Sud-ouest de la NouvelleCalédonie : Intégration des connaissances et modélisation spatialement explicite. PhD dissertation : Université de Nouvelle-Calédonie. 386 p.

3. Saltelli, A. 2004. What is sensitivity analysis ? In Sensitivity Analysis, pp. 3-13. Ed. by A. Saltelli, K. Chan, and E. M. Scott. Probability and Statistics Series. John Wiley, New York. 475 pp.

4. Droesbeke, J., Fine, J., and Saporta, G. 1997. Plans d’Expérience. Applications a` l’Entreprise. Technip, Paris. 509 pp. 